turer, for putting on sale last September a drug for the treatment of shingles from whose use 15 people died within weeks of the first supplies appearing in physicians' pharmacies (Nature 369, 697; 1994). The penalty is a serious one: Nippon Shoji must suspend all drug production for 105 days, a move that will cost the company many millions of dollars in lost sales. A more apt remedy would have been to suspend the salaries of the ministry's staff for a comparable length of time.

The story is not particularly complicated, but is otherwise strangely Japanese. The drug concerned is the antiviral agent called Sorivudine, offered for sale as a treatment for the adult form of chicken pox caused by herpes zoster and known as shingles. Nobody will dispute the need for treatments for this debilitating affliction, often of the elderly. So far as anybody can tell, it may even be an effective treatment for the affliction against which it was intended. The trouble is that Sorivudine, which is an artificially substituted derivative of uracil, can be fatal when administered together with fluorouracil anticancer drugs.

The formal basis for the penalty now levied against Nippon Shoji is that the company did not adequately warn physicians of the dangers of using the drug in combination with anticancer agents; its warning was not prominent on the packages of the drug, and did not mention fatality as a possible consequence of misuse. The ministry also complains that it was informed by the company of only one of three deaths occurring during the Phase III clinical trials of the drug, all apparently linked with the simultaneous use of fluorouracil anticancer agents, implying that Sorivudine might not have been licensed if the company had been more forthcoming.

That is a lame excuse. Elsewhere in the world, the conduct of the clinical trials of new drugs is organized as a quasijudicial process in which those responsible are required to keep accurate records of all patients, and to make those records available during the approval process. As a result, it is not necessary to suppose that those applying for approval for a new drug tell the licensing authority the truth or the whole truth; whatever they do, there is a high chance that the records will find them out. Of course, that takes time and skill. The ministry's long-standing fault has been its belief that the job can be done instead at hurried committee meetings bringing together the great, the good and the nowinactive.

It is a great shame that technically skilled Japan can do no better by pharmaceutical technology - and its own people. Yet the remedy has been plain for years. Costly though it will be, Japan needs a drug-approval system comparable in thoroughness with those of the United States and Western Europe. It also needs some way of weaning the Japanese population, the world's big spenders in this field, away from drugs of doubtful therapeutic value (see Nature 342, 850; 1989). The ministry's alternative, the scheme for installing a fax network to inform physicians quickly of new information on drugs, is not a remedy but merely a strip of sticking plaster. What Japan needs (and can afford) is a modern means of drug assessment.

\section{Drugs on the track}

Athletics authorities are right to ban performancerelated drugs, but should do so more intelligently.

Poor Britain, seemingly always at loggerheads with somebody about something, is now up to its neck in a squabble over the use of hormones for improving athletic performance. The circumstances are these. Ten weeks ago, a random drug test on a British woman competitor at an athletic competition in Portugal revealed abnormally high levels of testosterone (the "male" sex hormone which is also normally present at low concentrations in women). The first analysis has now been confirmed by analysis of a second urine sample by the same laboratory in Portugal.

That turn of events has diplomatic consequences. The British women's athletics team had qualified to compete in what is called the World Cup, arranged for this coming weekend, only because of the performance of the woman now suspected of having taken testosterone artificially; she can run 800 metres faster than most other women. If the finding of improper use were already confirmed, the British team's performance at qualifying competitions would be amended retrospectively, and the team would no longer be eligible to compete. But the woman has exercised her right to appeal, and the British team has decided to compete.

All this is a nonsense, and an avoidable one. There are two cogent reasons why athletes are banned from taking drugs. First, it is a means of cheating. Second, many of the proscribed drugs are dangerous to athletes' health. So how to police the use of drugs in sport? The obvious difficulty is that the temptation to use performance-enhancing drugs must be greatest for the least successful athletes, those struggling to win the attention of amateur athletics clubs to which they belong, and through which they might win fame and (now) fortune. That explains why national athletics associations have taken to random testing.

But they have a responsibility to make a better job of it. For one thing, if there are always two urine samples, why are they not analysed independently at separate laboratories? Second, why is there not a third sample, collected for the suspected athlete's own use? Third, while positive results from tests on well-known athletes are invariably made public, why are not negative results also made public? That way, at least, it would be possible to form an objective view of the prevalence of drug-taking in athletics.

There are also physiological questions to be tackled. Athletics authorities suspicious of dosing for testosterone seek a measurement of the ratio of the active hormone to its precursor, epitestosterone (said by the Sports Medical Centre in Lisbon to have been $42: 1$, or much greater than the normal). Given the frequency with which these measurements are now made, the athletics authorities are themselves best placed to say what is the expected normal range of values of this ratio in athletes, who may by their training differ from other people. But in the absence of the routine publication of the data, even that is an obscure question. $\square$ 